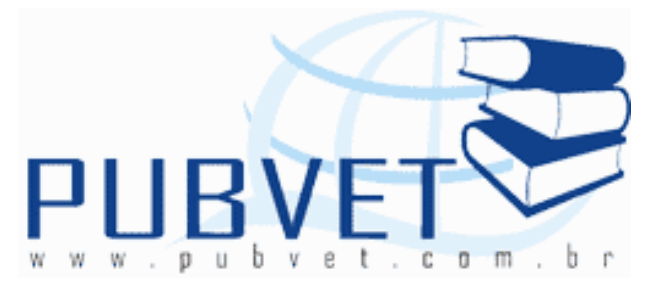

PUBVET, Publicações em Medicina Veterinária e Zootecnia.

\title{
Controle de emissão de gases e odores na indústria avícola: Caso amônia
}

\section{Jairo Alexander Osorio Saraz ${ }^{(1)}$, Adriana Garcia do Amaral( ${ }^{(2)}$, Flávio Alves}

Damasceno $^{(3)}$, Ilda de Fátima Ferreira Tinôno(4), Olga Lucía Zapata Marín ${ }^{(5)}$

(1) Professor Assistente, Departamento de Engenharia Agrícola, Universidade Nacional de Colombia. E-mail: aosorio@unal.edu.co.

(2) Professora Assistente, Instituto de Ciências Agrárias e Ambientais, Universidade Federal de Mato Grosso, Sinop.

E-mail: adrianagamaral@gmail.com.

(3) Doutorando em Construções Rurais e Ambiência, Departamento de Engenharia Agrícola, Universidade Federal de Viçosa, Viçosa.

E-mail: flavio.damasceno@ufv.br

(4) Professora Adjunta, Departamento de Engenharia Agrícola, Universidade Federal de Viçosa, Viçosa. E-mail: iftinoco@ufv.br.

(5) Mestranda em Construções Rurais e Ambiência, Departamento de Engenharia Agrícola, Universidade Federal de Viçosa, Viçosa.

E-mail: olluzama@gmail.com.

\section{Resumo}

Nos últimos tempos tornou-se crescente a preocupação com os impactos ambientais causados pela produção animal e os resíduos advindos desta. Dessa forma, esta revisão tem por objetivo descrever de forma breve temas 
SARAZ, J.A.O. et al. Controle de emissão de gases e odores na indústria avícola: Caso amônia. PUBVET, Londrina, V. 5, N. 32, Ed. 179, Art. 1205, 2011.

que vem ganhando destaque no cenário avícola mundial, como é o controle de emissões de amônia e de odores gerados na produção. Com esse trabalho foi possível observar que para mitigar o impacto ambiental da avicultura é necessário um adequado planejamento, zoneamento e capacitação de todo o pessoal envolvido na criação das aves e no manejo de seus resíduos. Entretanto, foi constatada a existência de muitos métodos que apresentam grande eficiência nas reduções de amônia, no entanto de elevado custo de implementação.

Termos para indexação: Emissão de gases, poluição do ar, avicultura.

\section{Emission gas control and odors in the poultry industry: Ammonia case}

\section{Abstract}

It has recently become a growing concern about the environmental impacts caused by livestock and their waste. Thus, this review aims to briefly describe issues that has gained prominence in the global poultry scenario, for example, control of emissions of ammonia and odors generated in production. This work, we observed that to mitigate the environmental impact of poultry need adequate planning, zoning and training of all personnel involved in the creation of birds and the management of their waste. However, it has been found that there are many methods that show great efficiency in the reduction of ammonia, however the high cost of implementation.

Index terms: Emission of gases, air pollution, poultry

\section{Introdução}

Várias abordagens têm sido sugeridas e avaliadas para a redução das emissões de amônia a partir das excretas animal, como a redução da excreção de nitrogênio através de manipulação dietética, redução de amônia volátil no estrume, urina e segregação de fezes para diminuir a perda de amônia.

Quando o controle sobre a urina e as fezes não é uma opção, os inibidores da uréase também podem ser usados para reduzir ou eliminar a 
SARAZ, J.A.O. et al. Controle de emissão de gases e odores na indústria avícola: Caso amônia. PUBVET, Londrina, V. 5, N. 32, Ed. 179, Art. 1205, 2011.

hidrólise da uréia em amônia. Métodos para reduzir a amônia volátil no estrume incluem a redução do $\mathrm{pH}$, alterando o equilíbrio acido-base em favor de amônio mais amônia.

Outros métodos para mitigar as emissões da amônia das superfícies, incluem a captura do gás no ar (usando capa física) com o objetivo de tratar o ar capturado para remover a amônia, usando para isso, bio-filtros ou bio-cobre, e lavadores. (Oviedo et al., 2008).

Os odores dos galpões de frangos são resultantes da degradação microbiana de uma variedade de compostos orgânicos da cama, incluindo as fezes (O'Neill et al., 1992). A concentração do odor pode ser mensurada pelo método do limiar absoluto olfatométrico, ou seja, a intensidade, caráter e tom hedônico do odor são igualmente importantes para avaliar a percepção pública com relação à freqüência e duração do odor.

Devido à falta de evidências científicas, as emissões de odor das instalações avícolas não são reguladas mundialmente pela maioria dos governos, mas constituem um ponto freqüente de discórdia entre os produtores e as populacoes que moram proximasas granjas, com reclamações e preocupações com a saúde são cada vez maiores

Desta forma, esta trabalho tem por objetivo descrever de forma breve temas que vem ganhando destaque no cenário avícola mundial, sendo estes a redução de emissões de amônia e de odores gerados na produção e métodos que visem controlar estas variáveis.

\section{Quantificação de odores.}

A qualidade do ar no interior de edificações não industriais é obtida considerando o número de pessoas no ambiente, o tipo de atividade, o número de renovação de ar por hora e o tipo de ambiente. Para ambientes fechados, como, por exemplo, escritórios a qualidade pode ser determinada através de um índice de qualidade olfativa, conforme o modelo de Fanger (1988). 
SARAZ, J.A.O. et al. Controle de emissão de gases e odores na indústria avícola: Caso amônia. PUBVET, Londrina, V. 5, N. 32, Ed. 179, Art. 1205, 2011.

A unidade que quantifica a intensidade de uma fonte poluidora olfativa é o Olf que representa a poluição produzida por um individuo adulto com uma taxa metabólica de 58,2 W. $\mathrm{m}^{-2}$, em um ambiente não industrial realizando uma atividade sedentária e sobre condições de higiene e conforto. O Olftambem pode ser entendida como a poluição que uma pessoa produz, ocupada em trabalho sedentário e de higiene normal, um Olf cada dia e meio.

O conceito de DECIPOL é utilizado para refletir a percepção combinada do nariz e dos olhos para o sentido químico de um ambiente com sua carga de cheiros diversos e elementos irritantes contidos no ar. A unidade é definida

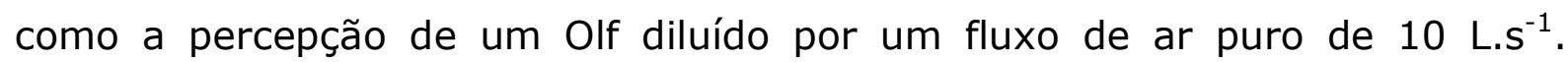
Assim, ocorre uma relação direta entre os decipoles presentes num determinado local e o número de pessoas insatisfeitas.

Dessa forma, em função dos decipoles torna-se possível qualificar um ambiente, edifícios com valores superiores a 10 decipoles são classificados como afetados pela Síndrome do Edifício Doente. Assim, utilizando os Olfs e os decipoles como unidades de poluição do ar, pode-se determinar a ventilação necessária no recinto.

Este tipo de metodologia pode ser adaptada e utilizada para determinar o grau de poluição numa estrutura avícola determinada, em função da percepção de odores.

Por outra parte, Lacey et al. (2004) da a conhecer que existe uma relação não-linear e diretamente proporcional entre a concentração e a intensidade do odor, a qual causa dificuldades em se concluir qual o efeito ocasionado. Assim, outro método possível de ser usado para quantificar o grau de poluição de uma estrutura aviaria pelos odores, é em função de medidas quantitativas de concentração de gases.

\section{Redução de emissões de amônia.}

O Brasil possui uma das maiores indústrias avícolas do mundo, posicionando-se como o terceiro maior produtor e maior exportador de carne 
SARAZ, J.A.O. et al. Controle de emissão de gases e odores na indústria avícola: Caso amônia. PUBVET, Londrina, V. 5, N. 32, Ed. 179, Art. 1205, 2011.

de frango do planeta. Assim, como a produção de frangos também pode afetar a qualidade do ar, por emissões de gases como amônia, exalação de odores, e produção de pó, na medida em que a industria vai crescendo maiores danos ambientais podem-se ter. Dentre esses gases, a amônia (NH3) é o poluente tóxico mais freqüentemente encontrado no interior das instalações zootécnicas, o qual causa danos a saúde e reduz a produtividade dos animais e das pessoas.

O controle de emissão de gases e por sem de odores na indústria avícola, pode ser feito por mecanismos internos e externos. Entre os mecanismos internos encontrasse a redução de excreção de nitrogênio de excretas, redução do nitrogênio volátil, redução do pH do estrume, ventilação e uso de ozônio no ar de aviários. Entre os externos destaca-se os processo de filtração e biofiltração, a utilização de coberturas permeáveis e impermeáveis, os sistemas purificadores (Scrubbers) e as barreiras vivas.

\subsection{Mecanismos internos}

\subsubsection{Redução de excreção de nitrogênio de excretas}

A minimização da excreção de nitrogênio dos dejetos através de modificações dietéticas é o primeiro passo para redução das emissões de $\mathrm{NH}_{3}$ provenientes de instalações agrícolas (Satter et al., 2002).

Os resultados de alguns trabalhos indicam que as dietas animais têm efeitos profundos nas emissões de $\mathrm{NH}_{3}$ provenientes do esterco excretado. Assim, na prática os esforços para reduzir as emissões de $\mathrm{NH}_{3}$ devem equilibrar desempenho animal, concentrações de proteína ideal e formulações da dieta (Cole et al., 2005; Panetta et al., 2006).

McGinn et al. (2002) e Clark et al. (2005), estudaram os efeitos da redução de proteina bruta $(\mathrm{PB})$ na dieta e concluíram que houve uma redução significativa na perda de $\mathrm{NH}_{3}$ de instalações de suínos. Resultados semelhantes foram obtidos por Otto et al. (2003), Hayes et al. (2004), Velthof et al. (2005) em instalações de aves. 
SARAZ, J.A.O. et al. Controle de emissão de gases e odores na indústria avícola: Caso amônia. PUBVET, Londrina, V. 5, N. 32, Ed. 179, Art. 1205, 2011.

Outras estratégias, como complemento da dieta com zeólita (Kim et al. 2005), antibióticos e probióticos (Han e Shin, 2005), óleo vegetal (Leek et al., 2004), extratos vegetais (ricos em taninos e saponinas) e enzimas exógenas (O'Connell et al., 2006) têm sido utilizados com sucesso variável para reduzir perdas de $\mathrm{NH}_{3}$.

\subsubsection{Redução do nitrogênio volátil}

Observa-se também que quando os fatores ambientais são constantes a volatilização de amônia a partir de estrume é predominantemente influenciada pelas concentrações de $\mathrm{NH}_{3}$ e ionizada $\mathrm{NH}_{4}{ }^{+}$em solução. Portanto, uma forma racional de reduzir a volatilização de $\mathrm{NH}_{3}$ é reduzindo as concentrações destas espécies voláteis de $\mathrm{N}$. Cinco abordagens comuns utilizadas para reduzir $\mathrm{N}$ voláteis incluem a segregação de urina-fezes, a inibição da hidrólise da uréia, a redução do $\mathrm{pH}$, a redução da amônia e bioconversão não-volátil das espécies de $\mathrm{N}$.

No caso da segregação de urina-fezes dois métodos têm sido testados. Um utiliza uma correia transportadora para separar urina e fezes, sendo a urina coletada em uma cova, enquanto as fezes são deixadas no cinto e transportadas para um poço de recolhimento seletivo (Stewart et al., 2004; Lachance et al., 2005). O outro drena a urina para longe das fezes em um buraco de urina imediatamente após a descarga usando desenhos de pisos adequados quando as fezes são raspadas ou lavadas em um separador de fezes (Swierstra et al., 2001).

Medeiros et al. (2008) avaliaram a redução da volatilização de amônia em cama de frangos por meio da adição de aditivos químicos em três experimentos usando diferentes doses de fosfato adicionadas à cama e outros aditivos como a sal de Glauber, enxofre, sulfato de cobre, fosfato, sulfato de alumínio e carbonato de sódio, onde foi constatado que o sulfato de cobre foi o melhor aditivo a inibir a volatilização (62\%), seguido do sulfato de alumínio $(53 \%)$ e o superfosfato simples $(43 \%)$. 
SARAZ, J.A.O. et al. Controle de emissão de gases e odores na indústria avícola: Caso amônia. PUBVET, Londrina, V. 5, N. 32, Ed. 179, Art. 1205, 2011.

Li et al. (2006) reportaram uma redução do $89 \%$ na volatilização de NH3 quando o alumínio foi aplicado a uma taxa de $2 \mathrm{~kg} \mathrm{~m}-2$ (sulfato de alumínio líquido). Armstrong et al. (2003) observaram que a aplicação do alumínio líquido equivalente a 0,5, 1,0 e 1,5 kg m-2 na cama de frango (sulfato de alumínio) foi eficaz em manter as concentrações de $\mathrm{NH} 3$ nas instalações inferior a 25 ppm para a segunda e terceira semana de criação.

Por outra parte o uso da zeólita que é um material de troca catiônica, que devido à suas propriedades cristalinas hidratadas decorrentes da uma infinita estrutura em 3 dimensões, possui uma afinidade elevada e seletividade para íons de NH4 (Mumpton e Fishman, 1977), é outra alternativa utilizada.

Uma camada de $38 \%$ zeólita colocada sobre a superfície de esterco de aves de compostagem reduziu as perdas de $\mathrm{NH} 3$ em um $44 \%$ (Kithome et al. 1999).

Witter et al. (1989) investigando a eficácia da zeólita na redução da perda de $\mathrm{NH} 3$ em estrume de aves, acharam uma insignificante redução de $1,5 \%$ na perda de $\mathrm{NH} 3$, quando foi misturada com estrume de suíno na proporção de 1:4. Nakaue et al. (1981) observaram uma redução de até 35\% da perda de $\mathrm{NH} 3$ pela adição de $5 \mathrm{~kg} \mathrm{~m}-2$ da zeólita na cama de frango.

\subsubsection{Redução do pH do estrume}

A volatilização da amônia está diretamente relacionada com a proporção de NH3 aquosa dentro do $\mathrm{N}$ amoniacal total (TAN) e, em geral, a uma temperatura e $\mathrm{pH}$ constante pode-se determinar o equilíbrio entre $\mathrm{NH} 4+\mathrm{e}$ $\mathrm{NH} 3$ com um pH mais baixo, favorecendo a formação de $\mathrm{NH} 4+$ e portanto, reduzindo o potencial de volatilização de $\mathrm{NH} 3$.

Deste modo, um baixo $\mathrm{pH}$ urinário pode ser um fator chave para a redução das emissões de NH3. Assim, diversos tratamentos dietéticos podem diminuir o pH urinário (Stockdale, 2005). Sais aniônicos (Bowman et al. 2003; Mellau et al., 2004) e alto teor de carboidratos fermentáveis (Mellau et al., 2004; Andersen et al., 2004) podem reduzir o pH urinário abaixo de 6,0. Em não-ruminantes, a acidificação da dieta com ácidos orgânicos (benzóico) ou 
SARAZ, J.A.O. et al. Controle de emissão de gases e odores na indústria avícola: Caso amônia. PUBVET, Londrina, V. 5, N. 32, Ed. 179, Art. 1205, 2011.

sais de Ca e P (Kim et al., 2004) também resultam em redução do pH urinário e das emissões de NH3.

Outros pesquisadores têm investigado à utilização de outros aditivos acidificantes,por exemplo, sulfato de alumínio ou potássio alumínio, cloreto férrico, sulfato de sódio e cloreto de cálcio, para reduzir as emissões de NH3 em estrume de bovinos (Armstrong et al., 2003; Li et al., 2006). Embora a maioria destes aditivos efetivamente levem a redução do $\mathrm{pH}$, geralmente não são tão eficazes em reduzir as perdas de $\mathrm{NH} 3$ como os ácidos fortes pois estes não podem manter estáveis as condições do $\mathrm{pH}$.

A aplicação de sulfato de alumínio líquido é eficaz na redução de emissão de amônia das camas de aves, que tem umidade menor do que $20 \%$, podendo conter a concentração de amônia em 25 ppm nas três primeiras semanas de produção. Esta aplicação deve ocorrer antes da entrada do lote. A alta acidez do sulfato de alumínio ajuda a reduzir os patógenos existentes, garantindo um ambiente mais saudável (Burns et al., 2008).

\subsubsection{Ventilação}

As ventilações naturais ou forçadas permitem alterações e controle nas estruturas, provendo oxigênio e eliminando gases como a amônia. A ventilação obedece a exigências térmicas e higiênicas diferentes. Na época de ventilação mínima, ocorre aumento de concentrações de poeira e gases como a amônia (Ronchi, 2004).

No interior de um alojamento avícola com ventilação natural existem três camadas de ar bem distintas: uma superior de ar quente com elevado teor de acido sulfídrico e amônia, uma intermediária de ar fresco recém introduzido e uma inferior de ar frio que se aquece rapidamente em contato com aves e vicia-se de dióxido de carbono pela respiração dessas (Tinoco, 2001; Osório et al., 2008).

Assim, faz-se necessário promover a remoção de gases no interior das edificações, tendo uma relação entre o gasto de energia por sistemas de ventilação e questões econômicas, deve-se ter vazões de ventilação mínimas 
SARAZ, J.A.O. et al. Controle de emissão de gases e odores na indústria avícola: Caso amônia. PUBVET, Londrina, V. 5, N. 32, Ed. 179, Art. 1205, 2011.

adequadas para inverno e para verão, dependendo do local de instalação do projeto.

\subsubsection{Ozônio no ar de aviários}

A aplicação de ozônio (O3) no ar dos galpões tem sido mencionada com uma tecnologia promissora para reduzir as emissões de amônia, poeira, odores e microorganismos no ambiente dos galpões avícolas (Yokoyama et al., 2000; Ullman et al., 2004).

O ozônio tem sido utilizado para purificar água por mais de um século, gerado pela reação fotoquímica da luz ultravioleta de $185 \mathrm{~nm}$ de longitude de onda, com o ar. Resultados preliminares do uso do ozônio mostraram reduções em NH3, nos odores e nas bactérias (Oviedo et al., 2008). No entanto, poucas pesquisas têm sido feitas para avaliar os efeitos destes sistemas de 03 nas aves e na sua capacidade de reduzir poluentes no ar dentro e fora dos aviários.

\subsection{Mecanismos externos}

\subsubsection{Filtração e biofiltração}

A filtração é mais um processo físico-químico, enquanto a biofiltração além de capturar também degrada biologicamente ou converte compostos presos em sua forma benigna. A remoção de $\mathrm{NH} 3$ do ar exalado utilizando filtros ou purificadores (água e ácido) é viável quando as instalações são ventiladas mecanicamente (Sommer e Hutchings, 1995).

O biofiltro é simplesmente uma camada de material orgânico, que abriga uma população de micróbios. O ar poluído é forçado a passar através deste material e convertido em dióxido de carbono e água. Fatores importantes que influenciam o desempenho do biofiltro é o tempo de passagem do ar poluído dentro do biofiltro e a umidade do material filtrante. Na maioria dos casos, as aplicações práticas desses dispositivos de limpeza são limitadas devido ao seu custo relativamente elevado e a problemas técnicos devido à poeira, especialmente nas instalações de aves e suínos. 
SARAZ, J.A.O. et al. Controle de emissão de gases e odores na indústria avícola: Caso amônia. PUBVET, Londrina, V. 5, N. 32, Ed. 179, Art. 1205, 2011.

Os biofiltros podem reduzir a emissão para o meio ambiente de $\mathrm{H} 2 \mathrm{~S}$ em até $95 \%$ e amônia em até $85 \%$ (Burns et al., 2008). Sun et al. (2000) descreveu um biofiltro, para remoção de NH3, de 200 milímetros de profundidade que consiste em uma mistura de composto e aparas de madeira usando um sistema de ventilação. Em média, este sistema de remoção teve uma eficiência de $83 \%$ de remoção de $\mathrm{NH}_{3}$.

Tanaka et al. (2003) também relataram uma redução de 94\% em remoção de $\mathrm{NH}_{3}$ do ar proveniente do sistema de compostagem de estrume animal, nas primeiras $72 \mathrm{~h}$ de tratamento, através de um biofiltro.

Nicolai et al. (2005), desenvolveram um tipo de biofiltro que leva em consideração o tamanho do leito, controle de umidade, operação e manejo, custo de operação e construção.

Em geral, a grande desventagen que apresentam os biofiltros alem de os seus altos custos, é que estes são usados principalmente para estruturas fechadas, enquanto que para estruturas abertas com ventilação natural, sem ajuda de outros mecanismos como as coberturas impermeáveis é difícil de usar este tipo de sistemas.

\subsubsection{Coberturas permeáveis e impermeáveis}

$\mathrm{O}$ método mais simples de controle para reduzir as emissões de $\mathrm{NH}_{3}$ em instalações abertas é utilizar uma cobertura física impermeável em conjunto com lavadores ou biofiltros para conter as emissões. As eficiências destas coberturas dependem da eficácia do biofiltro e de seu uso combinado. As coberturas permeáveis são feitas de materiais como palha, espuma, tecido geotêxtil e outros. Alguns dos desempenhos das coberturas impermeáveis e permeáveis são resumidos na Tabela 1 (Ndegwa et al., 2008). 
SARAZ, J.A.O. et al. Controle de emissão de gases e odores na indústria avícola: Caso amônia. PUBVET, Londrina, V. 5, N. 32, Ed. 179, Art. 1205, 2011.

Tabela 1 - Resume de alguns trabalhos de redução de amônia a partir de coberturas (Ndegwa et al., 2008)

\begin{tabular}{lcc}
\hline Tipo de cobertura & Redução da emissão (\%) & Referencias \\
\hline Polietileno & $80-100$ & Funk et al.(2006) \\
Filmes de oleo & $40-100$ & Heber et al. (2005) \\
Geotextil & 44 & Bicudo et al. (2004) \\
Cobertura de palha & $37-90$ & Guarino et al. (2006) \\
Aparas de madeira & $17-91$ & Guarino et al. (2006) \\
\hline
\end{tabular}

\subsubsection{Sistemas Purificadores (Scrubbers)}

Estes aparelhos são localizados nos ventiladores exaustores dos galpões de ventilação modo túnel. A desodorização e a captura de $\mathrm{NH}_{3}$ ocorrem quando o ar contaminado entra em contato com uma solução ou com água em spray que solubiliza e capturam a maior parte dos compostos químicos presentes no ar. Esta solução pode sofrer degradação microbiológica dos compostos.

A idéia é simples, mas na prática tem várias complicações como o alto custo inicial de implementação, necessidade de bombas, problemas de entupimento dos aspersores, problemas de variação na pressão da solução e, em geral, a manutenção (Ullman et al., 2004; Zhongchao e Zhang, 2004 citados por Oviedo et al., 2008).

\subsubsection{Isolamento das granjas com barreiras naturais}

As barreiras naturais com árvores nativas de cada região tem sido uma prática de biosegurança muito comum e importante na avicultura.

Informações científicas recentes (Malone et al., 2006; Patterson et al., 2008) demonstram que barreiras de árvores situados na frente dos exaustores das granjas podem capturar poeira e amônia, diminuindo entre 40 e 50\% o impacto ambiental da amônia e evitando que a vizinhança tenha contato visual direito com os galpões. 
SARAZ, J.A.O. et al. Controle de emissão de gases e odores na indústria avícola: Caso amônia. PUBVET, Londrina, V. 5, N. 32, Ed. 179, Art. 1205, 2011.

A técnica de uso das barreiras naturais pode parecer fácil, embora, para obter altas eficiências é necessário fazer estudos baseados no conhecimento da climatologia regional, ate à local, conhecendo aspectos tais como tendências dos ventos a través das plumas de dispersão, para determinar a distancia mais apropriada entre o aviário e a localização das barreiras.

\section{Considerações finais}

Existe uma relação direta entre as concentrações de gases e os odores, pelo, que podem ser usadas algumas metodologias para determinar em termos quantitativos a partir de que níveis de concentração estes começam a ser desagradáveis para o olfato humano.

Para mitigar o impacto ambiental da avicultura é necessário adequado planejamento, zoneamento e capacitação de todo o pessoal envolvido na criação das aves e no manejo de seus resíduos.

Ainda que existam muitos métodos que apresentem grandes eficiências nas reduções de amônia, a maioria tem um alto custo de implementação e ainda não estão muito difundidos, sendo que no nível de mecanismos internos a nutrição das aves é um dos principais métodos para reduzir a geração de amônia e externos o uso de barreiras naturais, ainda na maioria das industrias avícolas estas não sejam calculadas em função do conhecimento da climatologia regional e local.

\section{Referências bibliográficas}

ANDERSEN, J. B.; FRIGGENS, N. C.; LARSEN, T.; VESTERGAARD, M.; INGVARTSEN, K. L. Effect of energy density in the diet and milking frequency on plasma metabolites and hormones in early lactation dairy cows. Journal of Veterinary Medicine Series A, v. 51, p. 5257, 2004.

ARMSTRONG, K. A.; BURNS, R. T.; WALKER, F. R.; WILHELM, L. R.; RAMAN, D. R. Ammonia concentrations in poultry broiler production units treated with liquid alum. Proceedings of the Air Pollution from Agriculture Operations III, Research, Triangle Park, North Carolina, p. 116$122,2003$. 
BOWMAN, G. R.; BEAUCHEMIN, K. A.; RODE, L. M. Acidification of urine by feeding anionic products to non-lactating dairy cows. Canadian Journal of Animal Science, v. 83, p. 319-321, 2003.

BURNS, R.; MOORE, P. A.; MOODY JR, L. Using liquid aluminium sulphate to reduce poultry housing ammonia emissions. Mitigating air emissions from animal feeding operations conference, Iowa StateUniversity, 2008.

CLARK, O. G.; MOEHN, S.; EDEOGU, I.; PRICE, J.; LEONARD, J. Manipulation of dietary protein and nonstarch polysaccharide to control swine manure emissions. Journal of Environmental Quality, v. 34, p. 1461-1466, 2005.

COLE, N. A.; CLARK, R. N.; TODD, R. W.; RICHARDSON, C. R.; GUEYE, A., GREENE, L. W; MCBRIDE, $\mathrm{K}$. Influence of dietary crude protein concentration and source on potential ammonia emissions from beef cattle manure. Journal of Animal Science, v.83, p. 722-731, 2005

FANGER, P.O. The olf and decipol. ASHRAE J. 35-38. 1988

HAN, Y. K.; SHIN, H. T. Effects of antibiotics, copper sulfate and probiotics supplementation on the performance and ammonia emission from slurry in growing pigs. Journal Animal Science Technology, v.47, p. 537-546, 2005.

HARTUNG, J.; PHILLIPS, V. R. Control of gaseous emissions from livestock buildings and manure stores. Journal Agricultural Engineering Research, v. 57, p. 173-189,1994.

HAYES, E. T.; LEEK, A. B. G.; CURRAN, T. P.; DODD, V. A.; CARTON, O. T.; BEATTIE, V. E; O'DOHERTY, J. V. The influence of diet crude protein level on odour and ammonia emissions from finishing pig houses. Bioresource Technology, v. 91, p. 309-315, 2004.

KIM, I. B.; FERKET, P. R.; POWERS, W. J.; STEIN, H. H.; VAN KEMPEN, T. A. T. G. Effects of different dietary acidifier sources of calcium and phosphorus on ammonia, methane and odorant emission from growing-finishing pigs. Asian Australasian Journal Animal Science, v.17, p.1131-1138, 2004.

KIM, J. H.; KIM, S. C.; KO, Y. D. Effect of dietary zeolite on the performance and carcass characteristics of finishing pigs. Journal of Animal Science and Technology, v.47, p.555-564, 2005.

KITHOME, M.; PAUL, J. W.; BOMKE, A. A. Reducing nitrogen losses during simulated composting of poultry manure using adsorbents or chemical amendments. Journal of Environmental Quality, v.28, n.1, p. 194-201, 1999.

LACEY, R.E.; MUKHTAR, S.; CAREY, J.B.; ULLMAN, J.L. A review of literature concerning odors, ammonia, and dust from broiler production facilities: 1 . Odor concentrations and emissions. Journal of Applied Poultry Research v.13, n.1 p.500-508, 2004

LACHANCE JR, I.; GODBOUT, S.; LEMAY, S. P.; LAROUCHE, J. P.; POULIOT, F. Separation of pig manure under slats: to reduce releases in the environment. ASAE Paper No. 054159, 2005.

LEEK, A B G.; BEATTIE, V. E.; O'DOHERTY, J. V. The effects of dietary oil inclusion and oil source on apparent digestibility, faecal volatile fatty acid concentration and manure ammonia emission. Animal Science, v.79, p.155-164, 2004.

LI H; XIN H; BURNS R T (2006). Reduction of ammonia emission from stored poultry manure using additives: zeolite, Al+ clear, Ferix-3, and PLT. ASAE Paper No. 064188, 2006 ASABE Annual International Meeting, Portland, Oregon 
MALONE, G.; VAN WICKLEN, G.; COLLIER, S.; HANSEN, D. Efficacy of vegetative environmental buffers to capture emissions from tunnel ventilated poultry houses. In Proceedings Workshop Agric. Air Qual.: State of the Science, Potomac, MD. North Carolina State Univ., Raleigh, p. 875-878, 2006

MCGINN, S. M.; KOENIG, K. M.; COATES, T. Effect of diet on odorants emissions from cattle manure. Canadian Journal of Animal Science, v. 82, p. 435-444, 2002.

MEDEIROS, R.; SANTOS, B. J. M.; FREITAS, M.; SILVA, O. A.; ALVES, F. F.; FERREIRA, E. A adição de diferentes produtos químicos e o efeito da umidade na volatilização de amônia em cama de frango. Ciência Rural, v.38, p.2321-2326. 2008.

MELLAU, L. S. B.; JORGENSEN, R. J.; BARTLETT, P. C.; ENEMARK, J. M. D.; HANSEN, A. K. Effect of anionic salt and highly fermentable carbohydrate supplementation on urine $\mathrm{pH}$ and on experimentally induced hypocalcaemia in cows. Acta Veterinária Scandinavica, v.45, p.139$147,2004$.

MUMPTON, F. A.; FISHMAN, P. H. The application of natural zeolites in animal science and aquaculture. Journal of Animal Science, v. 45, n.5, p. 1188-1203, 1977.

NAHM, K. H. Current pollution and odor control technologies for poultry production. Avian Poultry Biology Review, v.14, p. 151-174, 2003.

NAKAUE, H. S.; KOELLIKER, J. K.; PIERSON, M. L. Effect of feeding broilers and the direct application of clinoptilolite (zeolite) on clean and re-used broiler litter on broiler performance and house environment. Poultry Science, v. 60, p.1221, 1981.

NDEGWA. P. M.; HRISTOV, A. N.; AROGO, J.; SHEFFIELD, R. E. A review of ammonia emission mitigation techniques for concentrated animal feeding operations. Biosystems Engineering, v.100, n.4, p.453-469. 2008.

NICOLAI, R.; SCHMIDT, D. Biofilters south Dakota State University, South Dakota counties and U.S Department of Agriculture cooperating. 2005.

O'CONNELL, J. M.; CALLAN, J. J.; O'DOHERTY, J. V. The effect of dietary crude protein level, cereal type and exogenous enzyme supplementation on nutrient digestibility, nitrogen excretion, faecal volatile fatty acid concentration and ammonia emissions from pigs. Animal Feed Science and Technology, v.127, n.1, p.73-88. 2006.

O'NEILL, D.H., STEWART, I.W.; PHILLIPS, V.R. A review of the control of odour nuisance from livestock buildings: Part 2. The costs of odour abatement systems as predicted from ventilation requirements. Journal of Agricultural Engineering Research v.51, n.2 p.157-165, 1992.

OSORIO, J. A. S.; TINOCO, I. F. F. Polución del aire en las estructuras pecuarias, emisiones y controles. Congreso Nacional de Ingeniería Agrícola. Medellín-Colombia. Octubre 11 de 2008.

OTTO, E. R.; YOKOYAMA, M.; HENGEMUEHLE, S.; BERMUTH, R. D.; VON KEMPEN, T.; VAN TROTTIER, N. L. Ammonia, volatile fatty acids, phenolics, and odor offensiveness in manure from growing pigs fed diets reduced in protein concentration. Journal of Animal Science, v.81, p.1754-1763, 2003.

OVIEDO-RONDÓN, E. O. Tecnologias para mitigar o impacto ambiental da produção de frangos de corte. Revista Brasileira de Zootecnia, v.37, n.1 p.239-252. 2008. 
PANETTA, D. M.; POWERS; W. J.; XIN, H.; KERR, B. J.; STALDER, K. J. Nitrogen excretion and ammonia emissions from pigs fed modified diets. Journal of Environmental Quality, v.35, p.1297-1308, 2006.

PATTERSON, P. H.; ADRIZAL HULET, R. M.; BATES, R. M.; DESPOT, D. A.; WHEELER, E. F.; TOPPER, P.A. The Potential for Plants to Trap Emissions from Farms with Laying Hens. 1. Ammonia. Journal of Applied Poultry Research v.17, p.54-63, 2008.

RONCHI, C. Principais práticas de manejo para aves recém nascidas. Editora Animal World. Numero 6, p. 26-30, 2004.

SATTER, L. D.; KLOPFENSTEIN, T. J.; ERICKSON, G. E. The role of nutrition in reducing nutrient output from ruminants. Journal of Animal Science, v.80, n.2, p. 143-156, 2002.

SOMMER S G; HUTCHINGS $\mathrm{N}$ J. Techniques and strategies for the reduction of ammonia emission from agriculture. Water Air and Soil Pollution, v. 85, n.2, p. 237-248, 1995.

STEWART, K. J.; LEMAY, S. P., BARBER; E. M., LAGUE, C.; CROWE, T. Experimental manure handling systems for reducing airborne contamination of fecal origin. ASAE Paper No. 044132, St Joseph, MI, 2004.

STOCKDALE, C R. Investigating the interaction between body condition at calving and precalving energy and protein nutrition on the early lactation performance of dairy cows. Australian Journal of Experimental Agriculture, v.45, p.1507-1518, 2005.

SUN, Y.; CLANTON, C J.; JANNI, K A.; MALZER G L. Sulfur and nitrogen balances in biofilters for odorous gas emission control. Transactions of the ASAE, v.43, n.6, p. 1861-1875, 2000.

SWIERSTRA D., BRAAM C R., SMITS M C. Grooved floor system for cattle housing: ammonia emission reduction and good slip resistance. Applied Engineering in Agriculture, v.17, n.1, p. 85-90, 2001

TANAKA A; YAKUSHIDO K; SHIMAYA C (2003). Adsorption process for odor emission control at a pilot scale dairy manure composting facility. Proceedings of the Air Pollution from Agricultural Operations III Conference, p. 189-196, North Carolina.

TINÔCO, I. F. F. Avicultura industrial. Novos conceitos de materiais, concepções e técnicas construtivas disponíveis para galpões avícolas Brasileiros. Revista Brasilera de Ciência Avícola, v. 3, n.1, 2001.

ULLMAN, J.L., MUKHTAR, S., LACEY, R.E., CAREY, J.B. A review of literature concerning odors, ammonia, and dust from broiler production facilities: 4. Remedial management practices. Journal of Applied Poultry Research v.13, p.521-531, 2004.

VELTHOF G L., NELEMANS J A., OENEMA O., KUIKMAN P J. Gaseous nitrogen and carbon losses from pig manure derived from different diets. Journal of Environmental Quality, v.34, p. 698706, 2005.

WITTER, E.; KIRCHMANN H. Effects of addition of calcium and magnesium salts on ammonia volatilization during manure decomposition. Plant and Soil, v.1154, p. 53-58, 1989.

YOKOYAMA, M.T., MASTEN, S.J. Effectiveness of ozonation as a manure treatment. In: Proceedings of 2000 National Poultry Waste Management Symposium. Eds. Blake, J. P. and Patterson, P. H., Auburn University Printing Service, AL 36849, USA. p. 85-91, 2000. 